\title{
Soziale Not in der Rechtsprechung des EGMR
}

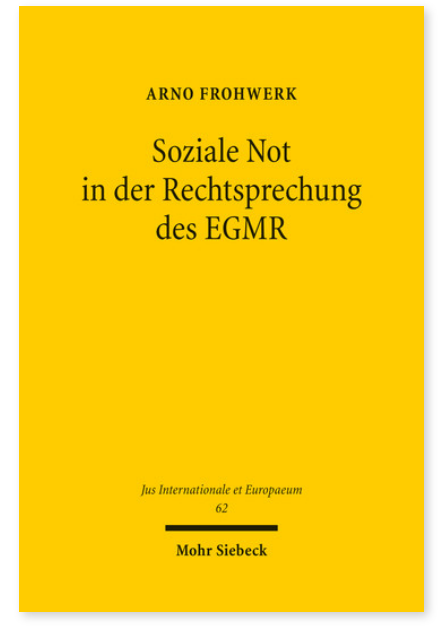

2012. XVIII, 380 Seiten. JusIntEu 62

ISBN 978-3-16-151938-3

DOI 10.1628/978-3-16-151938-3

eBook PDF $89,00 €$

ISBN 978-3-16-151700-6

fadengeheftete Broschur $89,00 €$
Arno Frohwerk untersucht den konventionsrechtlichen Umgang mit sozialer Not. Er analysiert dafür die Rechtsprechung des Europäischen Gerichtshofes für Menschenrechte und kommt zu dem Ergebnis, dass die Anwendung der EMRK auf soziale Not vom EGMR im Einzelfall auf den Ausnahmefall begrenzt wird. Soziale Leistungsrechte zum Schutz vor sozialer Not können nur dann gewährleistet werden, wenn ihre Nichtgewährung einen Verstoß gegen die Menschenwürde darstellt. Aus der Analyse des Einzelfallrechtes entwickelt er ein an der Rechtspraxis orientiertes Kriterienmodell, mit dem dieser Ausnahmefall konkret festgestellt werden kann.

Im ersten Teil der Untersuchung legt Arno Frohwerk dar, dass die EMRK grundsätzlich kein Instrument zur Gewährleistung sozialer Rechte ist. Anschließend unternimmt er eine detaillierte Analyse der Spruchpraxis in Hinblick auf die am Einzelfall orientierten temporären, persönlichen und außergewöhnlichen Umstände. Dafür stellt Arno Frohwerk die Entscheidungen, in denen keine Konventionsverletzung festgestellt worden ist, den Ausnahmefällen gegenüber, in denen der EGMR eine Verletzung festgestellt hat. Durch diese Gegenüberstellung werden die Kriterien sichtbar, die den Europäischen Gerichtshof bei seiner Entscheidung im Einzelfall lenken. Im dritten Teil wird das vom EGMR gewährleistete Existenzminimum aus einer rechtspolitischen und rechtstheoretischen Perspektive schließlich erklärt und bewertet. Abschließend werden die Ergebnisse dann mit einem Kriterienmodell operabel gemacht und Anwendungsfälle herauskristallisiert.

Arno Frohwerk Geboren 1980; Studium der Rechtswissenschaft in Gießen; Studium des internationalen Rechts in Gießen und an der University of Warwick; 2011 Promotion; seit 2010 Referendar im Landgerichtsbezirk Gießen.

\section{Jetzt bestellen:}

https://mohrsiebeck.com/buch/soziale-not-in-der-rechtsprechung-des-egmr-9783161519383?no_cache=1 order@mohrsiebeck.com

Telefon: +49 (0)7071-923-17

Telefax: $+49(0) 7071-51104$ 